\title{
Effect of $\beta$ radiation on success of glaucoma drainage surgery in South Africa: randomised controlled trial
}

\author{
James F Kirwan, Simon Cousens, Lynette Venter, Colin Cook, Andries Stulting, Paul Roux, Ian Murdoch
}

\begin{abstract}
Objective To evaluate whether $\beta$ radiation may offer a practical method of improving surgical success for glaucoma drainage surgery in South Africa.

Design Double blind, randomised controlled trial.

Setting Three public hospitals in South Africa.

Participants 450 black Africans with primary glaucoma.

Interventions Trabeculectomy with $1000 \mathrm{cGy} \beta$ radiation or standard trabeculectomy without $\beta$ radiation (placebo).

Main outcome measures Primary outcome measure was surgical failure within 12 months (intraocular pressure $>21$ $\mathrm{mm} \mathrm{Hg}$ while receiving no treatment for ocular hypotension). Secondary outcomes were visual acuity, surgical reintervention for cataract, and intraoperative and postoperative complications.

Results 320 people were recruited. $\beta$ radiation was given to $164 ; 20(6 \%)$ were not seen again after surgery. One year after surgery the estimated risk of surgical failure was $30 \%(95 \%$ confidence interval $22 \%$ to $38 \%$ ) in the placebo arm compared with $5 \%(2 \%$ to $10 \%)$ in the radiation arm. The radiation group experienced a higher incidence of operable cataract (18 participants) than the placebo group (five participants; $\mathrm{P}=0.01)$. At two years the estimated risks with placebo and $\beta$ radiation were, respectively, $2.8 \%(0.9 \%$ to $8.3 \%)$ and $16.7 \%$ $(10.0 \%$ to $27.3 \%)$.

Conclusion $\beta$ radiation substantially reduced the risk of surgical failure after glaucoma surgery. Some evidence was, however, found of an increased risk for cataract surgery (a known complication of trabeculectomy) in the $\beta$ radiation arm during the two years after surgery.

Trial registration ISRCTN62430622.
\end{abstract}

\section{Introduction}

Glaucoma is the world's second most common blinding condition causing irreversible visual loss. ${ }^{12}$ The prevalence of primary open angle glaucoma is often higher in people of African descent than in white people. ${ }^{3}$ Clear evidence shows that lowering intraocular pressure reduces the rate of progression..$^{5-7}$

In many low income countries surgery is the principal means of managing glaucoma. In African patients a successful outcome of glaucoma surgery is often compromised by an aggressive healing response. ${ }^{89}$ For this reason antimetabolites such as 5 -fluorouracil or mitomycin C may be used.

$\beta$ radiation has features that make it appealing for use in glaucoma surgery. Application is rapid and simple: both dose and treatment area can be controlled accurately. The probe is self sterilising and has a working life of 20 years or more. In settings without regular supplies and maintenance, $\beta$ radiation is particularly attractive.

Two randomised controlled trials on $\beta$ radiation in trabeculectomy have been published. Both involved white patients, in whom success rates for primary surgery are high. Four of 70 patients receiving $\beta$ radiation and seven of 56 controls were classified as failures (intraocular pressure $>21 \mathrm{~mm} \mathrm{Hg}$; $\mathrm{P}=0.18){ }^{10}{ }^{11}$ We evaluated the effect of $\beta$ radiation for glaucoma drainage surgery in South African patients.

\section{Participants and methods}

We carried out a double blind, randomised controlled surgical trial of trabeculectomy with $1000 \mathrm{cGy} \beta$ radiation or standard trabeculectomy without $\beta$ radiation (placebo) in three centres in South Africa. All black Africans with established glaucoma requiring trabeculectomy were invited to participate in the trial. Written, informed consent was obtained. Eligibility criteria were age 40 years or more, characteristic glaucomatous changes in the optic disc, an intraocular pressure $\geq 21 \mathrm{~mm} \mathrm{Hg}$ on at least one visit before listing for surgery (measured by Goldmann applanation tonometry), and an open angle on gonioscopy (see bmj.com for exclusion criteria). We included one eye of each patient.

Recruitment was between November 1999 and June 2002. A trial ophthalmologist collected the data. Visual field testing was not an outcome; testing increases the duration and cost of examinations.

Throughout the trial we obtained a median interobserver agreement of $2.8 \mathrm{~mm} \mathrm{Hg}$, with $95 \%$ limits. Visual acuity was measured using a reduced logarithm of the minimum angle of resolution (logMAR) tumbling $\mathrm{E}$ test. ${ }^{12}$ We assessed cataract using the LOCS (lens opacities classification system) III grading system. ${ }^{13}$ Although the observers had received training, we found variation between them. We therefore used the need for surgical intervention as an indicator of clinically important cataract.

Trabeculectomy surgery was modified from Cairn's original description. After conjunctival closure an applicator was placed over the surgical site, providing a dose of $1000 \mathrm{cGy}$ for active applicators. Patients were prescribed prednisolone acetate and chloramphenicol $0.5 \%$ four times daily postoperatively. The surgeons were experienced in ophthalmic surgery. All surgical events were recorded.

\section{Randomisation, masking, and follow-up}

Each centre had two applicators, one active and one placebo. The identity of the active applicator was known only to IM and SC,

Exclusion criteria are on bmj.com 
neither of whom participated in data collection. Randomisation was in blocks of 20, with the assigned groups distributed to each centre in opaque, sealed envelopes. Each participant was allocated a trial number on recruitment. The envelope with that number was opened during surgery to determine allocation. Separate record sheets were used at follow-up to mask clinicians from the treatment allocation.

Patients were followed up at one day; one or two weeks; and $1,3,6$, and 12 months after surgery, with subsequent review encouraged.

\section{Dosimetry of $\beta$ radiation}

The $\beta$ radiation emitters contained strontium- $90 /$ yttrium-90 (strontium-90 decays to yttrium-90 on release of the $\beta$ particle) in $8 \mathrm{~mm}$ disc applicators (SI-20; Nycomed Amersham, Buckinghamshire). Dosimetry was measured in the medical physics department, University of the Free State.

\section{Outcomes}

The primary outcome measurement was surgical failure within 12 months, defined as an intraocular pressure greater than 21 $\mathrm{mm} \mathrm{Hg}$ while receiving no treatment for ocular hypertension. Secondary outcomes were visual acuity, surgical reintervention for cataract, and intraoperative and postoperative complications.

\section{Statistical analysis}

The trial was designed to show a difference in surgical failure rates at 12 months. Assuming 50\% failure in the placebo arm and less than $30 \%$ in the radiation arm, we determined that we would need 268 participants to give $90 \%$ power with $5 \%$ significance. Allowing for $20 \%$ losses to follow-up, we estimated that we needed to recruit 334 participants.

Data were double entered into a bespoke database (Access 2000; Microsoft, WA). Analyses were carried out on an intention to treat basis. We plotted Kaplan-Meier survival curves of time to surgical failure and need for cataract surgery by treatment group and compared these using the log rank test. Cox regression was used to estimate the failure rate ratio between the two groups while controlling for other prognostic factors. We compared the treatment arms for changes in visual acuity using the last recorded visual acuity, which could be later than the date of surgical failure. The degree of change was classified into three categories: <0.25 logMAR, 0.25-0.39 logMAR, or $\geq 0.40$ $\operatorname{logMAR}$. We considered changes from better than count fingers to count fingers, from count fingers to perception of light, and from perception of light to no perception of light as equivalent to changes greater than $0.4 \operatorname{logMAR}$. We appointed a group of independent experts to monitor safety.

\section{Results}

Overall, 320 of 450 patients requiring trabeculectomy were randomised; 164 to the $\beta$ radiation group (fig 1 and table 1 ). Twenty participants $(6 \%)$ dropped out of the study after surgery. Some evidence was found that the probability of not being seen was associated with sex (women $10 \% v$ men $4 \%: \mathrm{P}=0.03$ ), blindness in the fellow eye $(9 \% \cup 3 \%: \mathrm{P}=0.02)$, and centre (Bloemfontein $2 \%$, Edendale $9 \%$, Pretoria 3\%: $\mathrm{P}=0.09$; table 1 ). No strong evidence was found for an association with other variables. A further 68 patients were lost to follow-up before 12 months (36 in the radiation arm). Similar mean numbers of follow-up visits were completed in each of the treatment groups (4.9 radiation group; 4.5 placebo group; $\mathrm{P}=0.35$ ).

Participants who were followed up showed similar distributions for sociodemographic, ophthalmic, and surgical factors in the treatment arms (table 1).

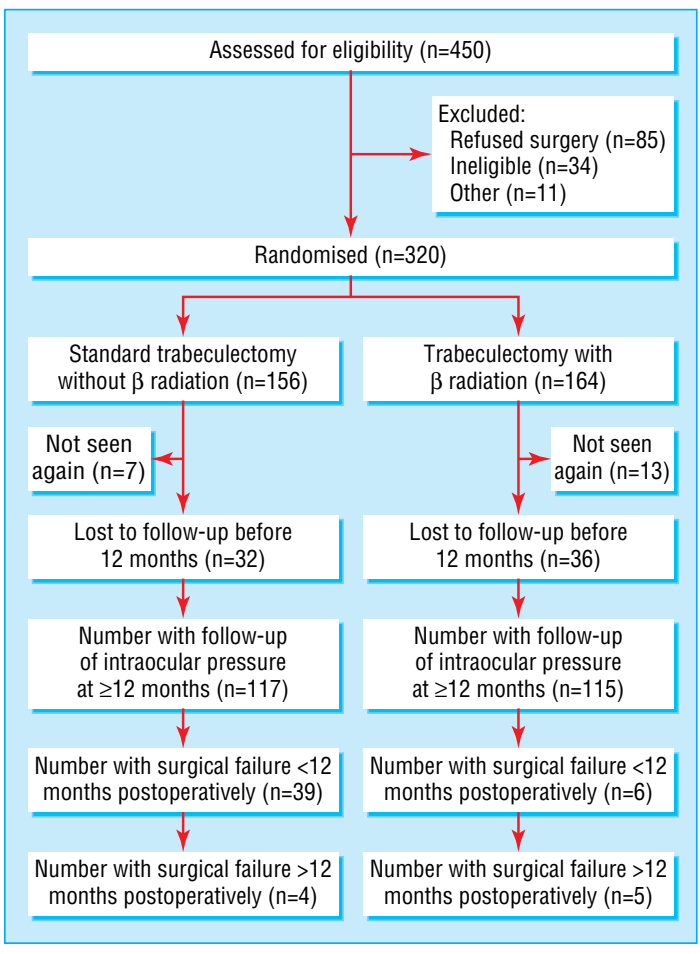

Fig 1 Flow of participants through trial

\section{Primary outcome: surgical failure}

A total of 54 cases of surgical failure (median intraocular pressure $>21 \mathrm{~mm} \mathrm{Hg}$ ) were identified. Figure 2 presents Kaplan-Meier survival curves for the two groups. Strong evidence was found of a lower risk of surgical failure in the radiation group ( $\log$ rank test $\left.\chi^{2}=26.1 ; \mathrm{P}<0.0001\right)$. The estimated risk of failure 12 months after surgery in the placebo arm was $30 \%$ (39 cases of surgical failure, $95 \%$ confidence interval $22 \%$ to $38 \%$ ) and in the radiation arm was $5 \%$ (six cases, $2 \%$ to $10 \%$ ). In the placebo arm the risk was $21 \%$ (high) in the first six months after surgery, rising to $30 \%$ at 12 months and $32 \%$ at 18 months. In the radiation group the risk was $2 \%$ (low) in the first six months, rising to $5 \%$ at 12 months and $9 \%$ at 18 months.

Eleven cases of surgical failure in the radiation group represent 4.8 per 100 person years. In the placebo group, 43 cases of surgical failure represent 26.0 per 100 person years. Failure rates across different subgroups were consistently lower in the radiation group. After fitting a Cox regression (proportional hazards) model, the estimated failure rate ratio in the radiation group compared with the placebo group was $0.21 \quad(95 \%$ confidence interval. 0.11 to 0.40 ; likelihood ratio test $\chi^{2}=27.7$, $\mathrm{P}<0.0001$ ). Controlling for each of the personal, ophthalmic, and surgical factors individually did not result in any important change to the estimated rate ratio (range 0.19-0.22).

Among patients not experiencing surgical failure and with at least six months of follow-up, the median intraocular pressure in the radiation arm at last follow-up was $11.5 \mathrm{~mm} \mathrm{Hg}$ (interquartile range $8.5-14.0 ; \mathrm{n}=115$ ) and in the placebo arm was $13.5 \mathrm{~mm} \mathrm{Hg}$ (11.0-16.0; $\mathrm{n}=82)$. After taking account of baseline intraocular pressure, strong evidence was found that intraocular pressures were lower in the radiation group than in the placebo group $(\mathrm{P}<0.001$, linear regression analysis). The median reduction in intraocular pressure in the radiation group was $17 \mathrm{~mm} \mathrm{Hg}$ compared with $16 \mathrm{~mm} \mathrm{Hg}$ in the placebo group. In relative terms, the radiation group experienced a median reduction in intraocular 
Research

Table 1 Distribution of personal, ophthalmic, and surgical factors in participants with primary glaucoma randomised to $\beta$ radiation or placebo and those followed up

\begin{tabular}{|c|c|c|c|c|}
\hline \multirow[b]{2}{*}{ Variable } & \multicolumn{2}{|c|}{$\beta$ radiation group } & \multicolumn{2}{|c|}{ Placebo group } \\
\hline & No randomised ( $n=164$ ) & $\begin{array}{l}\text { No }(\%) \text { with follow-up } \\
(n=151)\end{array}$ & No randomised ( $n=156$ ) & No $(\%)$ with follow-up $(n=149)$ \\
\hline \multicolumn{5}{|l|}{ Age (years): } \\
\hline $40-49$ & 21 & $21(14)$ & 18 & $17(11)$ \\
\hline $50-59$ & 32 & $29(19)$ & 34 & $32(21)$ \\
\hline $60-69$ & 50 & $48(32)$ & 55 & $53(36)$ \\
\hline$\geq 70$ & 61 & $53(35)$ & 49 & $47(32)$ \\
\hline Women & 72 & $65(43)$ & 59 & $53(36)$ \\
\hline Men & 92 & $86(57)$ & 97 & $96(64)$ \\
\hline \multicolumn{5}{|l|}{ Ethnic group: } \\
\hline Nguni & 112 & $100(66)$ & 108 & $102(68)$ \\
\hline Sotho & 42 & $41(27)$ & 45 & $44(30)$ \\
\hline Other & 10 & $10(7)$ & 3 & $3(2)$ \\
\hline \multicolumn{5}{|c|}{ Intraocular pressure at baseline $(\mathrm{mm} \mathrm{Hg})$ : } \\
\hline$<25$ & 43 & $42(28)$ & 38 & $37(25)$ \\
\hline $25-27.9$ & 48 & $43(28)$ & 33 & $33(22)$ \\
\hline $28-33.9$ & 41 & $37(25)$ & 41 & $38(26)$ \\
\hline$\geq 34$ & 32 & $29(19)$ & 44 & $41(28)$ \\
\hline \multicolumn{5}{|l|}{ Type of glaucoma: } \\
\hline Primary open angle & 113 & $103(68)$ & 120 & $115(77)$ \\
\hline Exfoliation & 39 & $36(24)$ & 33 & $31(21)$ \\
\hline Other or unknown & 12 & $12(8)$ & 3 & $3(2)$ \\
\hline \multicolumn{5}{|l|}{ Visual acuity in operated eye: } \\
\hline $6 / 9$ or better & 26 & $25(17)$ & 32 & $32(22)$ \\
\hline $6 / 9$ to $6 / 18$ & 48 & $45(30)$ & 43 & $41(28)$ \\
\hline $6 / 18$ to $6 / 60$ & 57 & $49(32)$ & 50 & $49(33)$ \\
\hline Count fingers to $6 / 60$ & 10 & $10(7)$ & 12 & $10(7)$ \\
\hline Count fingers & 12 & $11(7)$ & 8 & $7(5)$ \\
\hline Perception of light & 11 & $11(7)$ & 9 & $8(5)$ \\
\hline \multicolumn{5}{|l|}{ Blind in fellow eye: } \\
\hline No & 78 & $74(49)$ & 71 & $71(48)$ \\
\hline Yes & 96 & $77(51)$ & 84 & $77(52)$ \\
\hline \multicolumn{5}{|l|}{ Nuclear opacity*: } \\
\hline $0-0.9$ & 6 & $6(4)$ & 4 & $4(3)$ \\
\hline $1-2.9$ & 95 & $89(59)$ & 98 & $93(62)$ \\
\hline$\geq 3$ & 56 & $50(33)$ & 47 & $46(31)$ \\
\hline Missing & 7 & $6(4)$ & 7 & $6(4)$ \\
\hline \multicolumn{5}{|l|}{ Nuclear colour*: } \\
\hline $0-0.9$ & 5 & $5(3)$ & 2 & $2(1)$ \\
\hline $1-2.9$ & 103 & $96(64)$ & 91 & $85(57)$ \\
\hline$\geq 3$ & 49 & $44(29)$ & 56 & $56(38)$ \\
\hline Missing & 7 & $6(4)$ & 7 & $6(4)$ \\
\hline \multicolumn{5}{|l|}{ Cortical cataract*: } \\
\hline $0-0.9$ & 36 & $32(21)$ & 47 & $44(30)$ \\
\hline $1-2.9$ & 101 & $95(63)$ & 84 & $81(54)$ \\
\hline$\geq 3$ & 20 & $18(12)$ & 17 & $17(11)$ \\
\hline Missing & 7 & $6(4)$ & 8 & $7(5)$ \\
\hline \multicolumn{5}{|c|}{ Posterior subcapsular cataract*: } \\
\hline $0-0.9$ & 63 & $59(39)$ & 72 & $69(46)$ \\
\hline $1-2.9$ & 86 & $79(52)$ & 66 & $63(42)$ \\
\hline$\geq 3$ & 8 & $7(5)$ & 10 & $10(7)$ \\
\hline Missing & 7 & $6(4)$ & 8 & $7(5)$ \\
\hline \multicolumn{5}{|l|}{ Treatment at baseline: } \\
\hline $\begin{array}{ll}\text { None } \\
\end{array}$ & 95 & $87(58)$ & 101 & $95(64)$ \\
\hline Topical only & 42 & $40(26)$ & 37 & $37(25)$ \\
\hline Oral or topical, or both & 27 & $24(16)$ & 18 & $17(11)$ \\
\hline \multicolumn{5}{|l|}{ Centre: } \\
\hline Bloemfontein & 25 & $25(17)$ & 20 & $19(13)$ \\
\hline Edendale & 89 & $79(52)$ & 86 & $80(54)$ \\
\hline Pretoria & 50 & $47(31)$ & 50 & $50(34)$ \\
\hline Surgical technique: & & & & \\
\hline Fornix based & 122 & $114(76)$ & 118 & $114(77)$ \\
\hline Limbal based & 42 & 37 (25) & 38 & $35(23)$ \\
\hline
\end{tabular}

*According to lens opacities classification system III. 


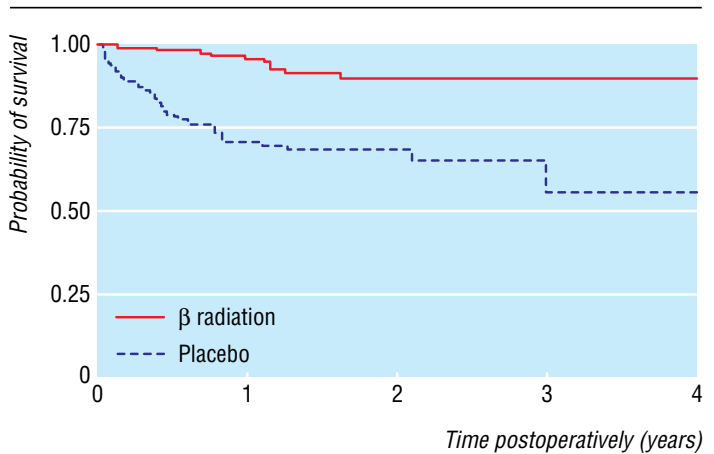

$\begin{array}{lccccccc}\text { Patients at risk } & & & & & & \\ \text { Time (years) } & 0 & 0.5 & 1 & 1.5 & 2 & 3 & 4 \\ \text { Placebo } & 149 & 97 & 75 & 44 & 24 & 7 & 2 \\ \beta \text { radiation } & 151 & 124 & 109 & 70 & 43 & 19 & 2\end{array}$

Fig 2 Survival times by treatment group after glaucoma drainage surgery in patients with an intraocular pressure $\leq 21 \mathrm{~mm} \mathrm{Hg}$

pressure of $61 \%$ compared with $55 \%$ for the placebo group. Figure 3 illustrates the change in intraocular pressure at six months or more for those who did not experience surgical failure.

\section{Secondary outcomes}

\section{Visual acuity}

The distributions of changes in visual acuity between the two groups after surgery using the last recorded visual acuity were similar $(\mathrm{P}=0.88)$. The mean duration of follow-up was 585 days in the radiation group and 532 days in the placebo group. Fifty eight per cent of participants in the placebo arm compared with $56 \%$ in the radiation arm had a measured change of $<0.25 \mathrm{log}$ MAR. Twenty six per cent of participants in the placebo arm and $28 \%$ in the radiation arm had measured deteriorations of $\geq 0.25$ logMAR.

\section{Surgical reintervention for cataract}

The radiation group experienced a higher incidence of cataract considered to need extraction than did the placebo group (18 v 5 participants; fig 4 ; $\log$ rank test $\mathrm{P}=0.01$ ). At one year postoperatively the risk of having developed a cataract requiring extraction in the placebo group was $0.8 \%(95 \%$ confidence interval $0.1 \%$ to $5.9 \%)$ and in the radiation group was $3.2 \%(1.2 \%$ to $8.3 \%)$. At two years the corresponding risks were $2.8 \%(0.9 \%$ to $8.3 \%)$ and $16.7 \%(10.0 \%$ to $27.3 \%)$. All participants who were identified as needing cataract extraction during follow-up had

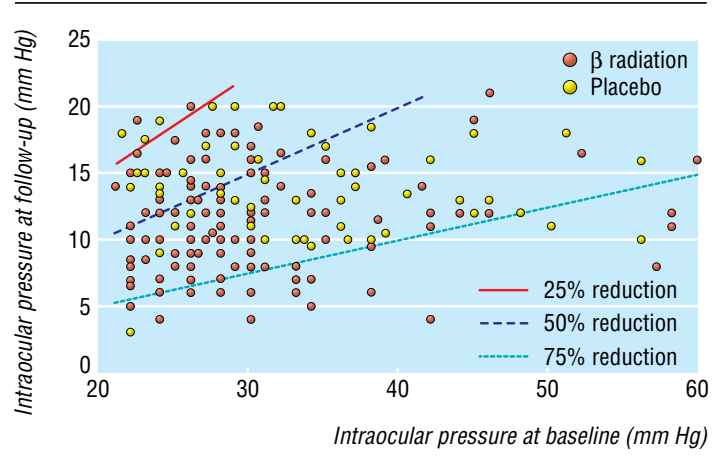

Only includes patients followed up for at least six months and who did not experience surgical failure

Fig 3 Intraocular pressures at follow-up plotted against those at baseline by treatment group for glaucoma drainage surgery

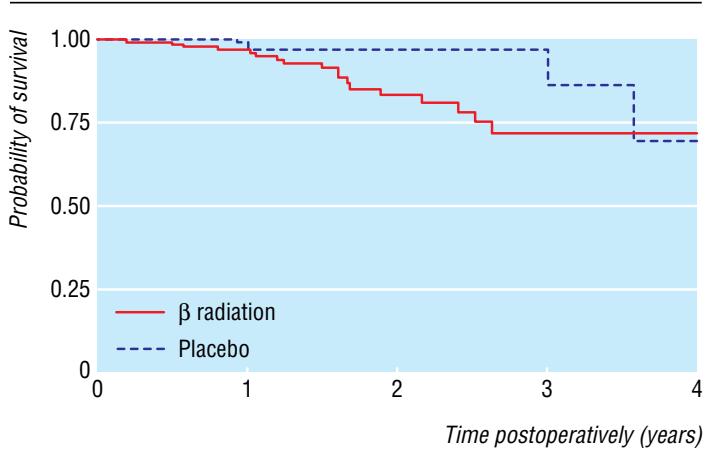

$\begin{array}{lccccccc}\text { Patients at risk } & & & & & & \\ \text { Time (years) } & 0 & 0.5 & 1 & 1.5 & 2 & 3 & 4 \\ \text { Placebo } & 149 & 125 & 109 & 64 & 35 & 9 & 3 \\ \beta \text { radiation } & 151 & 125 & 110 & 68 & 42 & 18 & 2\end{array}$

Fig 4 Cataract-free survival times by treatment group

evidence of cataract at baseline. Their median (range) lens opacities classification scores at baseline were 2.8 (1.5-4.0) for nuclear opacity, 3.0 (1.0-4.0) for nuclear colour, 1.8 (0.1-3.6) for cortical cataract, and 1.0 (0.1-4.0) for posterior subcapsular cataract. Participants with pseudoexfoliation glaucoma were more likely to be identified as needing cataract surgery than those with primary open angle glaucoma ( 11 cases, rate $0.3 / 100$ person years $v 11$ cases, rate $3.5 / 100$ person years; $\mathrm{P}=0.007$ ). For both types of glaucoma there seemed to be an excess of cataract in the radiation group (primary open angle glaucoma, $8 v 3$ cases, $\mathrm{P}=0.10$; pseudoexfoliation, $9 \vee 2$ cases; $\mathrm{P}=0.08$ ). Mild cellular reaction in the anterior chamber $(\geq 1$ cell per high power field) in the first month after surgery seemed more common in the radiation arm than in the placebo arm $(51 \%$ v $40 \% ; \mathrm{P}=0.07)$ and was associated with an increased rate of cataract (15 cases, rate 8.4/100 person years $v 5$ cases, rate $2.5 / 100$ person years; $\log$ rank test $\mathrm{P}=0.02$ ). After controlling for mild cellular reaction in the anterior chamber in the first month postoperatively, the radiation group still showed some evidence of increased incidence of cataract (rate ratio 3.9, 95\% confidence interval 1.2 to 12.2 ; $\log$ rank test $\mathrm{P}=0.04$ ).

\section{Surgical complications}

The two most common intraoperative and postoperative complications were clinically important uveitis and hypotony, both of which were slightly more common in the radiation group (table 2). No patients with hypotony sustained visual loss. Severe complications associated with a reduction in vision were seen in five participants (1.6\%), two of whom had received placebo.

\section{Discussion}

$\beta$ radiation has a beneficial effect on intraocular pressure and is a useful adjunct to glaucoma drainage surgery in South African patients. Reduction of intraocular pressure in patients with glaucoma is accepted to be of benefit. ${ }^{6}$ Some evidence also suggests that the lower the pressure, the more protection is afforded. ${ }^{9}$

In our trial complications were low in the context of current literature. ${ }^{14-16}$ The major disadvantage of $\beta$ radiation we identified was an increase in the risk of surgical reintervention for cataract. Cataract formation after trabeculectomy is well described, but estimates vary (range 2-55\%). Compared with previous reports, there does not seem to be a striking increase in the incidence of cataract in our trial, even in the $\beta$ radiation group. $^{17-25}$ 
Table 2 Intraoperative and postoperative complications in patients randomised to $\beta$ radiation or placebo for glaucoma drainage surgery

\begin{tabular}{|c|c|c|c|c|c|c|c|}
\hline Complication & $\begin{array}{c}\text { No of participants } \\
\text { (No in } \beta \text { radiation } \\
\text { arm) }\end{array}$ & Interventions for complication & $\begin{array}{l}\text { Decrease in visual } \\
\quad \text { acuity }^{*}\end{array}$ & $\begin{array}{l}\text { Stable visual } \\
\text { acuity* }\end{array}$ & $\begin{array}{l}\text { Intraocular } \\
\text { pressure } \\
\text { controlled† }\end{array}$ & $\begin{array}{l}\text { Intraocular pressure } \\
\text { uncontrolled }\end{array}$ & Note‡ \\
\hline Anterior chamber trauma & $1(0)$ & $\begin{array}{l}\text { Cataract extraction plus intraocular } \\
\text { lens }\end{array}$ & - & 1 & 1 & - & 1 \\
\hline \multirow[t]{2}{*}{$\begin{array}{l}\text { Clinically significant } \\
\text { uveitis }\end{array}$} & 11(7) & Cataract extraction $(n=1)$ & 3 & - & - & 3 & - \\
\hline & & None $(n=10)$ & - & 6 & 6 & - & - \\
\hline \multirow[t]{2}{*}{ Flat anterior chamber } & $5(2)$ & $\begin{array}{l}\text { Cataract extraction, vitrectomy, } \\
\text { Molteno drainage implant }(n=1)\end{array}$ & 1 & - & - & 1 & - \\
\hline & & Revision $(n=1)$, none $(n=3)$ & - & 3 & 3 & - & - \\
\hline \multirow[t]{2}{*}{ Hypotony $(<6$ mm Hg) } & $8(6)$ & Revision $(\mathrm{n}=2)$ & - & 8 & 8 & - & - \\
\hline & & Cataract extraction $(n=2)$ & - & - & - & - & - \\
\hline $\begin{array}{r}\text { Suprachoroidal } \\
\text { haemorrhage }\end{array}$ & $1(0)$ & None & 1 & - & - & - & 2 \\
\hline Blebitis & $1(0)$ & None & - & 1 & 1 & - & - \\
\hline Misdosage & $1(1)$ & None & - & 1 & 1 & - & 3 \\
\hline Total & $28(16)$ & & 5 & 20 & 20 & 4 & 4 \\
\hline
\end{tabular}

*Decrease of more than 0.4 logarithm of the minimum angle of resolution units.

†Criteria for intraocular pressure as per trial, but participants with controlled intraocular pressure after revision or a second procedure are counted as having controlled intraocular pressure.

$\neq 1=C$ Cannula ejected from syringe into anterior chamber; $2=v e r y$ advanced glaucoma on presentation; $3=$ dose of about 2500 cGy applied in error; $4=$ some data missing due to losses to follow-up.

No patient had more than one complication.

One reason for the observed increased risk for cataract in the radiation arm could be that clinicians give more attention to cataract in the presence of controlled intraocular pressure. If this is so, we would expect those with controlled intraocular pressure to undergo further cataract surgery. This does not seem to be the case (data not shown).

$\beta$ radiation could itself cause cataract. $\beta$ radiation has extremely rapid attenuation, however-the calculated amount of radiation reaching the germinal epithelium of lenses in our trial was less than the minimum dose reported to cause cataract (200 cGy). ${ }^{26}{ }^{27}$ In addition $\beta$ radiation is often used on bare sclera to treat pterygia. Despite a larger dose of radiation to the lens, cataract is not common. Finally, radiation induced cataract is a characteristic pattern of cortical opacity, starting at the site of application. ${ }^{28}$ This pattern was not observed in our patients.

Extremely shallow anterior chambers have been linked with an increased risk of cataract formation. ${ }^{17}{ }^{18}$ In our study extremely shallow anterior chambers were rare. It has also been suggested that eyes with slightly low intraocular pressures (not normally classified as hypotony) may be at higher risk of cataract formation. Reports vary on the importance of this causal mechanism. ${ }^{19}{ }^{20}$ Lower intraocular pressures in the $\beta$ radiation arm could explain some of the increase in cataract risk.

We observed a higher incidence of mild uveitis among patients receiving $\beta$ radiation. Such an effect has not been reported previously. ${ }^{21}$ After controlling for mild uveitis, evidence of an association between $\beta$ radiation and risk of cataract remained. Uveitis therefore does not explain all of the increased risk.

The use of steroids during the postoperative period may induce cataract formation but would require differential use between the two groups. Randomisation and a similar pattern of follow-up visits in the two groups make this less likely. It may be that a combination of factors acts synergistically. The increased frequency of cataract formation in those with pseudoexfoliation syndrome has been noted previously. ${ }^{22}$

\section{Arguments for and against $\beta$ radiation}

$\beta$ radiation is carried out at the time of original glaucoma drainage surgery and does not require postoperative compliance or direct costs. It has a major, clinically important benefit on control of intraocular pressure and has appeal in resource poor settings as the probe is self sterilising, involves a one-off cost, can treat patients for 20 years or more, and requires no supplies.

If $\beta$ radiation increases the need for further surgery the advantages of single therapy with trabeculectomy are much diminished. Explaining glaucoma and the need for preventive intervention is extremely difficult. The possibility of further surgery may discourage uptake and place increased demands on the health system. A potential complication of subsequent cataract surgery is failure of the drainage bleb. ${ }^{29} 30$

Although blindness caused by cataract is reversible, blindness caused by glaucoma is not. Restoration of vision with subsequent cataract surgery must represent a better outcome than permanent blindness from glaucoma. The option of combined surgery (trabeculectomy with $\beta$ radiation plus cataract extraction) needs urgent study.

We thank Peter Constable, Rosemary Foley, Casper Willemse, and Louis Goedhals for information and advice on $\beta$ radiation; Johan van den Berg, Asgar Sahib, Rossi Stoyanova, Hendrick van Wyk, and Anthony Zabarowski for preliminary data analysis, quality control, and clinical support. Data collection and examination support was also undertaken by James Beatty, Jan Botha, Hussein Dawood, Stefano Gugliametti, Anton van Heerden, Sumaya Karrim, Kapil Moodley, Wayne Marais, Daniel Senekal, and Vanessa Thundstrum. We also thank the patients for their input and the community members who assisted in tracking down and encouraging maximum returns for review.

\section{What is already known on this topic}

The efficacy of glaucoma surgery in South Africa is limited by postoperative scarring

No universally accepted method exists for dealing with this problem

\section{What this study adds}

$\beta$ radiation as an adjunct to glaucoma drainage surgery in South African patients significantly improves surgical success rates over at least two years

The radiation group seemed to develop an excess of cataract 


\section{Research}

Contributors: All authors helped conceive the idea for the study, design the study, and analyse and interpret the data. IM, SC, and JFK drafted the manuscript. JFK, SC, PR, and CC revised the manuscript and provided statistical expertise. IM supervised the study and is guarantor.

Funding: This work was funded by the Wellcome Trust (grant Nos 068244 and 056045). Professors Gordon Johnson and Peng Khaw were coapplicants for the initial research grant.

Competing interests: None declared.

Ethical approval: This study was approved by the research ethics committees of all included centres, along with the Institute of Ophthalmology.

1 Quigley HA. Number of people with glaucoma worldwide. $\mathrm{Br} J$ Ophthalmol 1996;80:389-93.

2 Resnikoff S, Pascolini D, Etya'ale D, Kocur I, Pararajasegaram R, Pokharel GP, et al. Global data on visual impairment in the year 2002. Bull World Health Organ 2004;82:844-

3 Leske M. The epidemiology of open-angle glaucoma. Am J Epidemiol 1983;118:166-91.

4 Tielsch JM, Sommer A, Katz J, Royall RM, Quigley HA, Javitt J. Racial variations in prevalence of primary open-angle glaucoma. JAMA 1991;266:369-74.

5 The advanced glaucoma intervention study (AGIS): 7. The relationship between control of intraocular pressure and visual field deterioration. The AGIS Investigators. Am J Ophthalmol 2000;130:429-40.

6 Heijl A, Leske MC, Bengtsson B, Hyman L, Hussein M. Reduction of intraocular pressure and glaucoma progression: results from the early manifest glaucoma trial. Arch Ophthalmol 2002:120:1268-79.

7 Kass MA, Heuer DK, Higginbotham EJ, Johnson CA, Keltner JL, Miller JP, et al. The ocular hypertension treatment study: a randomized trial determines that topical ocular hypotensive medication delays or prevents the onset of primary open-angle glaucoma. Arch Ophthalmol 2002;120:701-13; discussion 829-30.

8 Broadway DC, Grierson I, Hitchings RA. Racial differences in the results of glaucoma filtration surgery: are racial differences in the conjunctival cell profile important? $\mathrm{Br}$ Ophthalmol 1994;78:466-75.

9 Ederer F, Gaasterland DA, Dally LG, Kim J, VanVeldhuisen PC, Blackwell B, et al. The advanced glaucoma intervention study (AGIS): 13. Comparison of treatment outcomes within race: 10-year results. Ophthalmology 2004:111:651-64.

10 Barnes RM, Mora JS, Best SJ. Beta radiation as an adjunct to low-risk trabeculectomy. Clin Exp Ophthalmol 2000;28:259-62.

11 Rehman SU, Amoaku WM, Doran RM, Menage MJ, Morrell AJ. Randomized controlled clinical trial of beta irradiation as an adjunct to trabeculectomy in open-angle glaucoma. Ophthalmology 2002;109:302-6.

12 Rosser DA, Laidlaw DA, Murdoch IE. The development of a "reduced logMAR" visua acuity chart for use in routine clinical practice. Br J Ophthalmol 2001;85:432-6.

13 Chylack LT Jr, Wolfe JK, Singer DM, Leske MC, Bullimore MA, Bailey IL, et al. The len opacities classification system III. The Longitudinal Study of Cataract Study Group. Arch Ophthalmol 1993;111:831-6.

14 Edmunds B, Thompson JR, Salmon JF, Wormald RP. The national survey of trabeculectomy. III. Early and late complications. Eye 2002;16:297-303.

15 Wilkins M, Indar A, Wormald R. Intra-operative mitomycin C for glaucoma surgery. Cochrane Darabase Sjst Reu 2001:CD002897.

16 Wormald R, Wilkins MR, Bunce C. Post-operative 5-fluorouracil for glaucoma surgery. Cochrane Database Syst Rev 2001:CD001132.

17 Costa VP, Smith M, Spaeth GL, Gandham S, Markovitz B. Loss of visual acuity after trabeculectomy. Ophthalmology 1993;100:599-612.
18 Ritch R, Shields MB, Krupin T. The glaucomas. Vol. III. In: Ritch R, ed. St Louis: Mosby, 1996.

19 Popovic V, Sjostrand J. Long-term outcome following trabeculectomy: I Retrospective analysis of intraocular pressure regulation and cataract formation. Acta Ophthalmol (Copenh) 1991;69:299-304

20 Vesti E, Raitta C. A review of the outcome of trabeculectomy in open-angle glaucoma. Ophthalmic Surg Lasers 1997;28:128-32.

21 Miller MH, Rice NS. Trabeculectomy combined with beta irradiation for congenital glaucoma. Br J Ophthalmol 1991;75:584-90.

22 Tornquist G, Drolsum LK. Trabeculectomies. A long-term study. Acta Ophthalmol (Copenh) 1991;69:450-4.

23 Yalvac IS, Sahin M, Eksioglu U, Midillioglu IK, Aslan BS, Duman S. Primary viscocanalostomy versus trabeculectomy for primary open-angle glaucoma: three-year prospective randomized clinical trial.J Cataract Refract Surg 2004;30:2050-7.

24 Lai J, Ho C. Trabeculectomy combined with beta irradiation in uncomplicated primary open angle glaucoma. Invest Ophthalmol Vis Sci 1994;34:1432. [Abstract.]

25 Quigley HA, Buhrmann RR, West SK, Isseme I, Scudder M, Oliva MS. Long term results of glaucoma surgery among participants in an east African population survey. BrJ Ophthalmol 2000;84:860-4.

26 Gleckler M, Valentine JD, Silberstein EB. Calculating lens dose and surface dose rates from $90 \mathrm{Sr}$ ophthalmic applicators using Monte Carlo modelling. Med Phys 1998;25:29-36.

27 Kirwan JF, Constable PH, Murdoch IE, Khaw PT. Beta irradiation: new uses for an old treatment: a review. Eye 2003;17:207-15.

28 Thomas CI, Storassi JP Friedell HL Lenticular changes associated with beta irradiation of the eve and their significance. Radiology 1962;79:588-97.

29 Chen PP, Weaver YK, Budenz DL, Feuer WJ, Parrish RK 2nd. Trabeculectomy function after cataract extraction. Ophthalmology 1998;105:1928-35.

30 Derbolav A, Vass C, Menapace R, Schmetterer K, Wedrich A. Long-term effect of phacoemulsification on intraocular pressure after trabeculectomy. J Cataract Refract Surg 2002;28:425-30.

(Accepted 23 August 2006)

doi 10.1136/bmj.38971.395301.7C

Department of Epidemiology and International Eye Health, Institute of

Ophthalmology, University College London, London EC1V 9EI

James F Kirwan research fellow

Ian Murdoch senior lecturer

Infectious Diseases Epidemiology Unit, London School of Hygiene and Tropical Medicine

Simon Cousens professor of epidemiology and medical statistics

Ophthalmology Department, National Hospital, Bloemfontein, Republic of South Africa

Lynette Venter consultant

Andries Stulting professor

Ophthalmology Department, Groote Schuur Hospital, Cape Town, Republic of South Africa

Colin Cook consultant

Ophthalmology Department, Pretoria Academic Hospital, Pretoria, Republic of South Africa

Paul Roux professor

Correspondence to: I Murdoch i.murdoch@ucl.ac.uk 